\title{
Researchers adapting to open access journal publishing: the case of the University of Cape Town
}

\author{
Reggie Raju ${ }^{1}$, Jill Claassen ${ }^{2}$ and Elizabeth Moll ${ }^{3}$ \\ reggie.raju@uct.ac.za ORCID: orcid.org/0000-0003-1465-0074 \\ jill.claassen@uct.ac.za ORCID: orcid.org/0000-0002-4618-2431 \\ elizabeth.moll@uct.ac.za ORCID: orcid.org/0000-0003-0773-8609
}

\begin{abstract}
Received: 22 January 2017
Accepted: 10 February 2017

This paper reports on the contribution of the openness movement to the changing mode of distributing scholarly literature. It is argued that the University of Cape Town (UCT), a leading research university on the African continent with relatively high research output, has a social justice obligation to distribute freely its scholarly research to the widest audience possible. Contributing to this social justice obligation through the sharing of research output via open access (OA) platforms are the university's progressive $O A$ policy and activities to ensure roll-out of the policy as well as its commitments to support article processing charges (APCs) and follow the global trend with regard to OA publishing. The authors, using a case study design, report that these factors have contributed to UCT's researchers adapting to publishing their journal articles on OA platforms. The investigation concludes that, in an era of fiscal constraints, the visibility of research is important to source funding and to meet the institution's social justice obligation; and therefore adapting to new publishing trends is an imperative for UCT researchers.
\end{abstract}

Keywords: Open access, open access publishing, article processing charges, social justice, scholarly communication, University of Cape Town

\section{Introduction}

The last decade has seen a major change in the way scholarly information is distributed. This change has significantly influenced the shaping of the scholarly literature landscape. Corroborating this assertion is the supposition by Chadwell and Sutton (2014) that the removal of barriers to the free exchange of information has transformed and will continue to transform the landscape of scholarly communication through the building of institutional repositories, publication in OA journals, hosting of Open Educational Resources, facilitation of access to research data, and the advocating for the passage of OA policies. Transformation is accelerated by the growth of the World Wide Web and the development of commensurate technology, making information ever more ubiquitous. The growth of the web has enhanced the capacity to share freely scholarly literature on a global scale, adding to the surfeit of information that already exists. However, as much as there is a glut of information available, in reality it is claimed that there is a dearth of scholarly information available to many as the cost of book, journal and other subscriptions has spiralled out of control.

The spiralling cost of subscriptions is one of the significant factors that has initiated, and is continuing to fuel, the growth of the openness movement. The spurred growth of the open access segment of the openness movement is testimony to the desire by OA advocates to make scholarly literature freely accessible to the end user; access to scholarly information is considered a public good. In terms of the African and South African context, the authors believe that OA should be considered a moral obligation and, furthermore, that it should be driven by a social justice ethos. Hence, their claim that a historically advantaged institution such as the University of Cape Town (UCT) should promote OA as part of its social responsiveness agenda en route to meeting its moral obligation to the advancement of a just society.

As a leading research university on the African continent, UCT has an obligation to share its research production freely and as widely as possible. This paper examines policies, practices and services rolled out by UCT to advance the sharing of research output. It is these policies, practices and services that will engender a culture among UCT researchers that will accelerate their adaptation to publishing on OA platforms. The authors are advocates of openness and would like to see that other institutions benefit from the lessons learnt by UCT in this area. The purpose of the paper is therefore to assist newcomers to the openness movement with circumventing the challenges that beset UCT and to build on this exemplar for the growth of openness, thus contributing to social justice in South Africa and Africa.

The primary focus of this paper is on UCT academic staff's journal article publishing patterns within the different OA streams that are on offer. The paper discusses the benefits of OA, focusing on a shift away from improved visibility and citations, towards social justice and the moral obligation of the researcher and/or institution. This shift entails a change in mind set and thus the need for a slightly more detailed discussion on the subject.

1. Reggie Raju (PhD), who is the corresponding author, is Deputy Director: Research and Learning Services, UCT Libraries, University of Cape Town

2. Jill Claassen is Assistant Director: Scholarly Communication and Research, Research and Learning Services, UCT Libraries, University of Cape Town

3. Elizabeth Moll is Junior Librarian, UCT Libraries, University of Cape Town 


\section{Definition, delimitations and assumptions of open access publishing}

It is not the intention of this paper to engage in a detailed discussion on the definition of $O A$, suffice to say that $O A$ is the explicit removal of price barriers (such as subscriptions, licensing fees, pay-per-view fees) and permission barriers (such as most copyright and licensing restrictions) to the end user. The emphasis is on freely available electronic scholarly literature at the point of use - highlighting the 'freeness' of scholarly literature to the end user. The focus of the discussion in this paper is on policies and practices to support publishing on OA platforms. Other areas of OA publishing are discussed, albeit very briefly, to demonstrate how some of the OA publishing puzzle pieces fit together.

It is assumed that it will not be long before publishing in an OA forum becomes the default practice of researchers. This assumption is not unfounded; many writers have alluded to the same eventuality. Björk and Solomon (2014) assert that OA scholarly publishing is currently evolving very rapidly, growing at about $30 \%$ a year based on article volume. Ilva, Laitinen, and Saarti (2016) are more forthright when they claim that "open access publishing will become the global norm that will be adopted in all countries". The transition to OA is given credence by the growth of the Directory of Open Access Journals (DOAJ) which imposes stringent criteria for inclusion on its platform. Laakso and Björk (2016) interrogated the platform to show the growth pattern of DOAJ. They found that the number of journals on the platform has increased substantially from 744 journals in 2000 to 6,713 in 2011 to 9,512 journals in 2014 (see Figure 1). It is worth noting that $74 \%$ of the 9,512 titles do not charge article processing charges ${ }^{4}$ (APCs) (Laakso \& Björk 2016: 920).

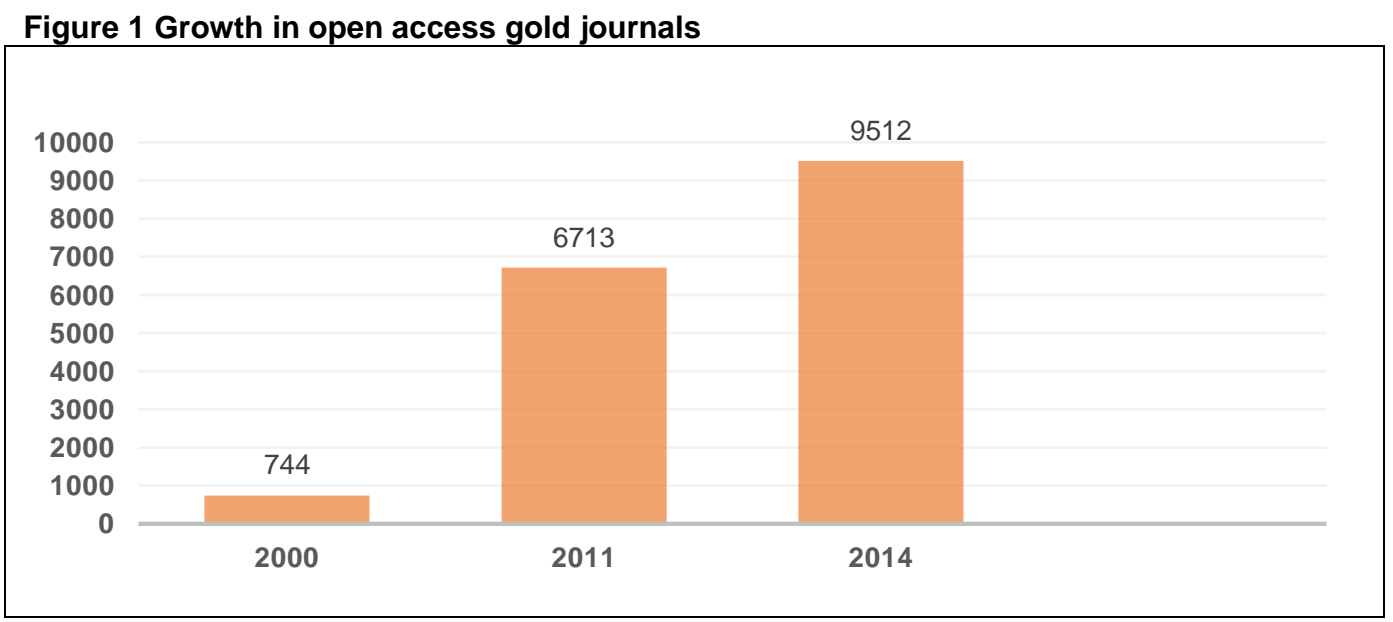

Data source Laakso and Björk (2016)

As much as there has been a substantial increase in the number of gold OA journals ${ }^{5}$, as inferred by the growth of the number of journals registered with DOAJ, there has been a significant increase in the number of hybrid journals (see Figure 2). Clearly, there is widespread increase in the number of journals that provide an OA option. Inferred from this growth pattern is that the number of journals that are completely closed - that is, a journal only accessible through subscription is diminishing rapidly.

Figure 2 Growth in number of hybrid journals

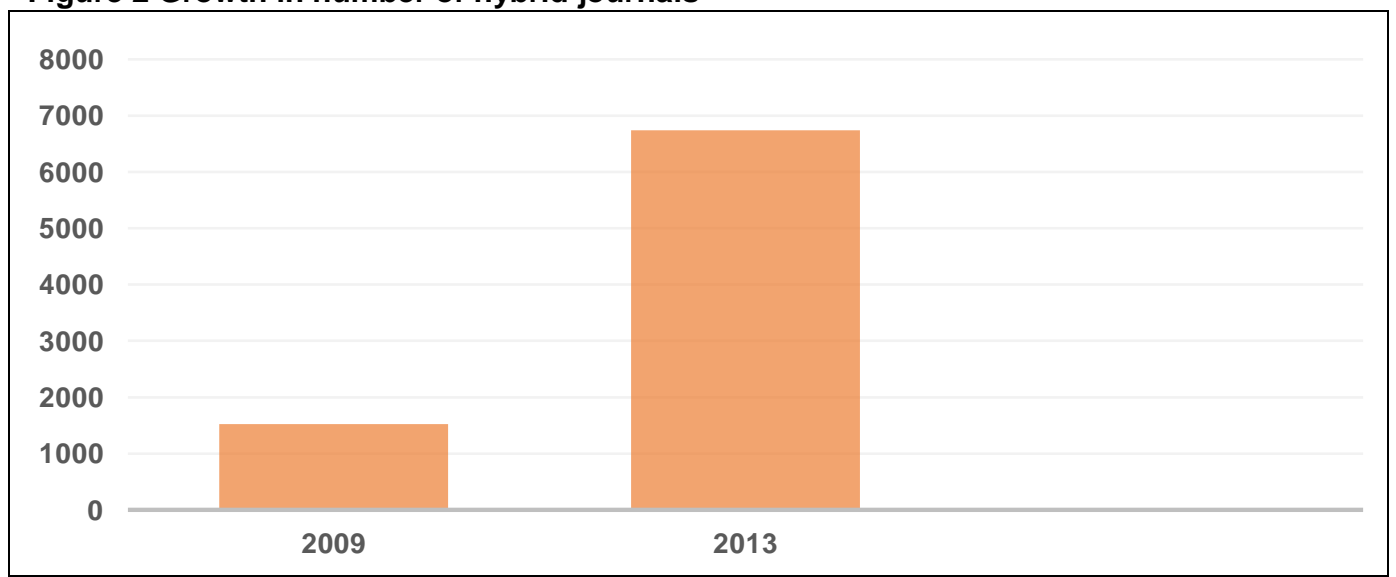

Source Björk and Solomon (2014)

4. An APC is a fee that the author, institution or funding agency pays to the publisher to make the article freely accessible to the end user immediately on publication

5. For definition of gold and hybrid journals see later discussion on the different models in open access 
Corresponding to the growth in the number of journals that offer an OA option (that is, both gold OA journals and hybrid journals) is the sizeable growth in the number of OA articles being published (Björk \& Solomon 2014). Laakso and Björk (2016: 924) present figures that show a radical increase in the growth of hybrid OA articles. In 2007, there were 666 hybrid OA articles in Elsevier, Springer, Wiley-Blackwell, Sage, and Taylor and Francis journals. By 2013, that number had increased to 13,994, a more than $2,000 \%$ increase in the number of hybrid articles published from 2007 to 2013 (Laakso \& Björk 2016).

The growth in the number of articles published in BioMed Central and other 'for profit' OA journals and hybrid journals indicates that, for researchers to publish their research articles on OA platforms, either institutions should have an APC budget or researchers should make provision in their grant applications for APC funding. As many gold OA journals charge APCs (of which the authors are not advocates but instead view as a phase towards openness), the need for the budget to pay these charges is confirmed. The exemplar of BioMed Central can be used to examine this need, viewed against the backdrop of the growth of OA articles published in their suite of journals: in July 2000, the total number of OA articles published was 20,700, in 2011 the total was 340,000; 482,361 in 2014 (see Figure 3) (DOAJ 2016).

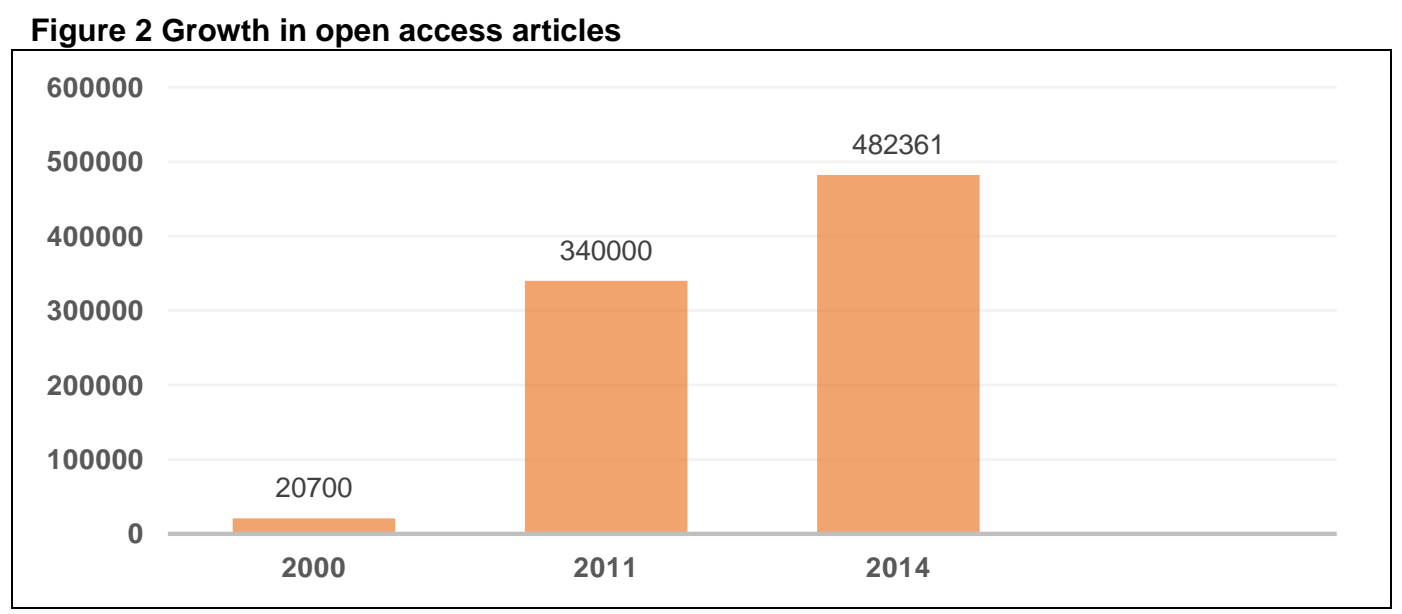

Data source DOAJ 2016

Taking their lead from assertions made in the literature and the growth patterns reflected in the most comprehensive non-commercial OA platform (that is, DOAJ), the authors examined ways in which publishing in an OA forum could become the default practice of researchers sooner rather than later. If UCT and other research-intensive African universities can adapt sooner, the likelihood of the remaining institutions in Africa joining the openness movement becomes a greater reality.

Before engaging in a discussion of the policies and practices that could facilitate quick and efficient adaptation to publishing in OA journals, it is important to discuss the different models of OA and the benefits of OA, especially within an African context. Such a discussion would provide some assistance in determining the reasons for the publishing adaptation patterns of UCT researchers.

\section{Models in open access}

As the open access movement matures, definitions of associated concepts become more nuanced with specific emphases placed, depending on the context in question. This paper will use the more generic definitions of the green and gold routes of $\mathrm{OA}$, the two alternative models for open accessibility to scholarly content. These two routes have their origins in the Budapest Open Access Initiative Declaration (2002). The green route, often referred to as self-archiving or the repository route, makes provision for the deposit of journal articles in an electronic archive. Bjork et al. (2014: 237) explain that "green open access is when such articles, usually in the form of the author manuscripts that preceded the finalised article, are made freely available somewhere on the web". The gold OA route, in the opinion of Crow (2002), has turned the conventional, commercial model for journal publishing on its head. There are two streams in terms of this new business model. The first stream is where established 'for profit' publishers make their content freely available to the end user. Since the primary objective of the publisher is to make a profit, in this case, the profit is generated, in the main, through the payment of APCs which are paid by the author, his/her academic institution or his/her funding agency. In this particular model, the entire journal is made accessible free to the end user. There is a second stream of gold OA publishing which is referred to as the hybrid model. The hybrid model provides the author or his/her institution with the option of paying a fee to make the specific article freely accessible to the end user.

Eger, Scheufen and Meierrieks (2015) point out that literature on the OA publishing model can be broadly categorised along three lines of research: (1) studies that assess the effectiveness of the alternative publishing models in enabling rapid and cost-efficient dissemination of scholarly work; (2) studies investigating how online and free online access have affected readership and citations; and, (3) studies focusing on researchers' attitudes towards OA and alternative publishing models. This paper is concerned with the third category and the adaptation of UCT researchers to publishing in OA forums against the backdrop of efforts by the university to share its research output. UCT has developed an OA policy (2014), which offers researchers the opportunity to deposit their output in an OA institutional repository. The policy also makes provision for the payment of APCs, which consequently gives researchers the opportunity to publish their output in hybrid or gold OA journals. 
It also allows for a diamond OA option to be offered at the university: that is, the hosting of OA journals by the institution itself.

\section{Benefits of open access}

Like most other higher education institutions (HEls) in the world, South African HEls seek to reap the benefits of OA. Institutions of higher education support the ideology that $\mathrm{OA}$ is the portal to the whole of a university's research output. Furthermore, $\mathrm{OA}$ is a means of marketing the university's research agenda across the globe. Using the green OA route that is, the deposit of journal articles into institutional repositories - HEls showcase their research output on the web in order to recruit research students. Another factor reinforcing the ideology is the benefit of institutional repositories to researchers. The growing exposure of research output via repositories contributes to an increase in article downloads and, ultimately, improved citation counts. A further benefit of $O A$ to both the institution and researchers is the knock-on effect of improved visibility contributing to increased collaboration among institutions and researchers. There is also evidence to suggest that improved visibility of research and research output increases the capacity to solicit funding (Jisc 2012, LeeHwa, Abrizah \& Noorhidawati 2012, Parker 2012).

To assist researchers with disseminating the results of their research through scholarly channels, libraries are increasing their services to the research community by offering to publish their work via the diamond OA route. Park and Shim (2011) point out that several libraries have recently launched library publishing services to support scholarly communication dissemination. According to Raju, Raju and Claassen (2015) there are currently four South African academic libraries that provide an OA publishing service.

Clearly, there are significant benefits for adopting OA practices at HEls. However, in the South African and African environments, the contention is that the benefit should be located within a social justice ethos: it is imperative that South Africa, and Africa as a whole, robustly pursue the sharing of research output as a public good.

\section{Africanising the benefits of open access}

The need to 'Africanise' the imperatives of OA was demonstrated by events that took place at South African HEls over the last twenty-four months (beginning around February 2015). The South African higher education (HE) sector in its entirety has been awakened by the call from student bodies for transformed and free quality higher education. The student protest leadership has sent out a strong call for the decolonisation of the curriculum. Any HEI not addressing this call, in the view of the authors, is burying its head in the sand. One of the ways in which HEls could address the call of students is through fast-tracking its library as publisher service. This service provides the library with the opportunity to contribute directly to a transformed and affordable education system. It provides opportunities to contribute to a society that is in desperate need of social justice.

The call for decolonised, affordable education demands inverting the pillars of OA which are currently implicitly and explicitly geared towards the global north. For South Africa and Africa, social justice and moral obligation should be the core explicit drivers of OA; showcasing individual and institutional output (mentioned earlier) become the implicit drivers of $O A$. The library as a publisher service gives libraries the flexibility to pursue the Africanisation of $O A$ as a concept. In the view of the authors, the drivers of an Africanised OA movement should pursue the quest for social justice. OA should be driven purely for philanthropic purposes; those institutions that are relatively advantaged have a moral obligation to share their output instead of using OA platforms principally to grow their profiles - emphasis, instead, should be on the development of the continent.

As much as the focus of this paper is on journal articles, it is useful to mention that a quick and tangible way of inverting the drivers is to publish open textbooks using open source software. The proposal is that open textbook agendas should not merely be around the conversion of hardcopy into digital format. Libraries as publishers need to understand the African context and make use of technology most prevalent in Africa for free textbook delivery, at the same time recognising the challenges faced with regard to access, such as bandwidth and electricity availability. The textbooks that libraries make available should be developed around these challenges. Likewise, the purpose of OA in the African context should be driven by a social justice ethos.

\section{Africanising the purpose of open access}

It is proposed that the common purpose of OA practices in South Africa be the reinforcement of the philosophy of sharing trusted and relevant scholarly content to generate new knowledge and for innovation. This 'purpose thread' resonates well with the African philosophy of Ubuntu. The synergy between OA and Ubuntu is underscored by the innate principle of sharing. Ubuntu is a Southern African term that brings to the fore socialism or humanism - it highlights the fact that one cannot exist as a human being in isolation (Chaplin 2006). Nestled and intertwined in the philosophy of Ubuntu are the unwritten and unacknowledged pillars of $\mathrm{OA}$, which are social justice and moral obligation. It is important to examine, albeit very briefly, these pillars as they individually and/or collectively uphold the founding principles of OA and should be, for all intents and purposes, the drivers of OA practices in South Africa.

Africa, including South Africa, has been subjected to years of colonialisation and, in the post-colonial period, has been ravished by inequality and deprivation. One of the significant contributors to Africa's continuance as the 'dark continent' is the deprivation of access to scholarly literature necessary to move Africa from the periphery of the world's knowledge production to the epicentre; access to knowledge will allow Africa to find solutions to current challenges that beset the continent (Raju 2016). 
Robinson (2016) views social justice as the promotion of a just society by challenging injustice. He purports that social justice advocates for a fair allocation of community resources: a community where people are not discriminated against, nor their welfare and well-being constrained. Social justice is generally equated with the notion of equality or equal opportunity in society. Rawls (2014) posits that social justice promotes the protection of equal access to liberties, rights, and opportunities, as well as taking care of the least-advantaged members of society. Miller (1999) adds that social justice is concerned with ways in which resources are allocated to the citizenry by social institutions - education and information are included as essential resources. The International Forum for Social Development (2006) directly links inequalities in the distribution of access to knowledge with social injustice. It has also linked the delivery of quality education to social justice. Education, including technical training and adult education, is critical for ensuring access to decent work and for social mobility, and in most societies is a strong determinant of social status and an important source of self-respect. In the South African context, social justice, as a normative term, refers to the extension of the principles of human dignity, equality, and freedom to participate in all of the political, socio-economic and cultural spheres of society. These principles are enshrined in the Constitution of the Republic of South Africa.

Moral obligation is the other pillar upholding OA. Moral obligation is viewed as a duty which one ought to perform, however there is no legal compulsion to do so. In the African and South African context, highly research-productive universities on the African continent have a moral obligation to share their research output with the rest of the continent. Furthermore, there has to be a conscious effort to develop open teaching material to support teaching, if not across the continent, at least across respective countries. Leading research universities in South Africa have a moral obligation to uphold the philanthropic principles of $\mathrm{OA}$ and to ensure that, in an unequal society, they pursue the principles of social justice as associated with the openness movement.

\section{South Africa's research production collaboration status}

Drawing from the comments of Kofi Annan (2000), former Secretary General of the United Nations, who asserted that "the university must become a primary tool for Africa's development in the new century [and that] universities can help develop African expertise", it is proposed that OA is one of the golden strands necessary to increase research to achieve desired African development. In addressing African rectors and vice chancellors, Tise (2011) claimed that South Africa produces $66 \%$ more research publications in Africa than the second-placed country, Nigeria. The authors acknowledge that South Africa's research publication status is inclusive of the contributions of traditional universities, comprehensive universities and universities of technology. Collectively, these institutions contribute significantly to the development needs of South Africa and Africa at large. Drawing from Chiware and Skelly (2016), the authors attribute South Africa's research output status to good collaboration with the global north and the fact that South African researchers are "better connected to external sources of knowledge". Chiware and Skelly (2016) also claimed that global north partners prefer to work with wellestablished scholars to advance knowledge generation.

South Africa's dominance as a global north research partner is reflected in a comparison with its BRICS peers. South Africa's 'research collaboration publication rate' is $53 \%$ while Brazil's is $25 \%$, China's $23 \%$ and India's $20 \%$. For all intents and purposes, "South Africa has become a regional hub for collaboration, given its relative strength in higher education, better funding schemes and policy frameworks, well developed research and ICT infrastructures..." (Chiware and Skelly 2016). However, Kahn (2011) cautioned that South Africa's research collaboration publication rate renders South Africa vulnerable should those collaborations weaken. Kahn (2011) advised that "there is no substitute for building the home base". UCT, with a significant research output, has a moral obligation to develop collaborations with other African universities and to grow Africa's knowledge production. As indicated, the one way of moving Africa from the periphery of the world's knowledge production to the epicentre is to stimulate collaboration and share research output.

\section{Open access at UCT: policy influence}

UCT's Intellectual Property (IP) Policy (2011: 3) states that it

encourages research and development and social outreach by creating a research culture that actively responds to the needs of the people of the Republic of South Africa, whilst also contributing to the global research community. In doing so, UCT seeks to protect the rights and privileges which members of the UCT community traditionally enjoy in the pursuit of knowledge, whilst at the same time balancing this with the philosophy of sharing information with others.

In terms of South African labour law and South Africa's copyright legislation, the copyright of research conducted and published as part of an employee's contract of employment belongs to the employer. However, in terms of UCT's IP Policy, copyright is re-routed to the author. Given this policy, UCT researchers have authority to cede copyright to the publisher of their research. In terms of this particular practice, UCT is an exception; the norm is where copyright is held by the institution. Technically, researchers at institutions that do not have an IP policy such as that of UCT do not have the prerogative to cede copyright to the publisher. Given UCT's policy, researchers there have a greater obligation to understand their rights pertaining to copyright. Researchers must become familiar with their right to retain copyright, while at the same time allowing publishers to distribute the published work.

Another policy that has significant influence on the rate of OA publishing is the OA policy of the National Research Foundation (NRF) of South Africa. The NRF Statement (2015) states that 
from 01 March 2015, authors of research papers generated from research either fully or partially funded by NRF, when submitting and publishing in academic journals, should deposit their final peer-reviewed manuscripts that have been accepted by the journals, to the administering Institution Repository with an embargo period of no more than 12 months.

However, if the paper is published in an OA journal or if the publisher allows the deposit of the published version in PDF format, that version should be deposited into an institutional repository and must be openly available. The NRF policy also makes provision for the data supporting the publication: the data should be deposited in an accredited OA repository with an allocation of a Digital Object Identifier (DOI) for future citation and referencing.

These mandatory policies give researchers leverage to challenge stringent publishing agreements. Researchers and their respective institutions are enabled to negotiate waiver agreements from publishers that would ensure that critical research output is freely accessible to the entire research community and society at large.

The pivotal UCT policy with regard to its commitment to OA is its Open Access Policy (2014: 4). The policy states that an author:

(a) must deposit an appropriate version [post peer review] of scholarly publications into an officially designated Institutional Repository or into an acceptable curatorial system which can be harvested by UCT; or

(b) if prevented by a publisher's copyright terms or other good reason from doing so, must notify the Institutional Repository in writing that he/she will not be doing so and the reasons for this.

UCT's OA Policy was passed by its Council in June 2014. There is an expectation that UCT researchers deposit a copy of their published articles in the institutional repository, OpenUCT. With the launch of OpenUCT in July 2014, there are now about 17,000 items available to the public of which over 3,000 are journal articles. Even though there is an expectation that researchers will deposit copies of their journal articles in OpenUCT in compliance with the OA Policy, there has not been a significant change in academic staff behaviour. The percentage of researchers self-archiving their output since the passing of the policy is less than $5 \%$ of the researcher cohort.

The authors are optimistic that the rate of self-archiving will increase as the policy matures and self-archiving gains momentum. As provided for by the policy, there are interventions that UCT Libraries have instituted to increase the rate of submission to the repository. The Libraries is engaging in mediated self-archiving through bulk ingestion of journal articles. It uses basic information provided by the university's Research Office, that is, the research output that is sent to the Department of Higher Education and Training (DoHET). The Research Office records are enriched with the addition of abstracts and, where the publishers' policies allow, the full text of the articles. In the near future, the Libraries will be using the Converis system to retrieve full metadata records and deposit them into OpenUCT. It is anticipated that the opportunities offered by Converis, in tandem with the OA Policy, will exponentially increase submission rates. As much as self-archiving rates of academic staff may not change considerably, the alternative provided by the Libraries will see a substantial growth in the number of research articles that are in the repository. Such an increase would contribute to the social justice pillar of OA.

The UCT OA Policy is deemed to be progressive, being one of few policies, nationally and internationally, that makes some provision for APCs. The policy states that the university will provide funding for APCs for subsidy-earning publications, where researchers are not able to source alternative funding for this purpose. The APCs fund is managed by UCT Libraries which has been responsible for the roll-out of this segment of the policy. Since its inception in 2014, the APCs fund supported seventy-five OA articles in 2014, sixty-four articles in 2015 and sixty-nine articles in 2016. It must be noted that the APCs fund was depleted by mid-year in each of the three years, while the demand for support has been on the increase.

Testimony to the university's commitment to OA, and in particular to the APCs fund, is the continuation of the fund despite severe university cost-saving exercises. At a time when UCT is going through an austerity process wherein budgets, including that of staff compensation, are being cut, the university has increased the APCs budget for 2017 by more than $40 \%$ of the 2016 allocation. The Libraries is projecting that it will be able to fund 585 articles in 2019 which is $33 \%$ of the projected number of research articles that will be published in that year. This is conditional on the university continuing to contribute toward an APCs budget; the projection is that the other $67 \%$ would be supported by funding agencies. The Libraries, in collaboration with the Research Office, will advise researchers to include a line item for APCs in their funding proposals. It is posited that the continuation of the APCs budget allocation, as projected by the Libraries, would contribute to the social justice pillar of OA.

In addition to the above-mentioned policies and practices, UCT Libraries has restructured its staff to provide greater support to the openness movement, thereby contributing to social justice. UCT Libraries is supporting diamond OA publishing by itself publishing scholarly OA journals, including international journals, using open source software. It has already published a number of OA monographs, including an open textbook. The changing role of academic libraries demands that libraries offer a publisher service (Raju 2016). This library as a publisher service facilitates free access to research by the reader and at no cost to the author. Providing diamond OA publishing responds to the OA pillars of philanthropy, social justice and moral obligation. 


\section{Current study}

As discussed earlier, UCT has put in place policies and has rolled out commensurate practices that are intended significantly to influence academic staff adapting to OA publishing. The underpinning philosophy is that the institution's commitment to OA practices must be aligned to the need for social justice. The authors investigated the influence of UCT's policies and practices in changing the publishing habits of its academic staff. Despite the fact that the OA Policy only came into effect in 2014, the publishing trends of UCT researchers over the last five years (2011-2015) were examined. The trends were examined using data on the journal scholarly output of UCT researchers from audited lists of the DoHET as well as the data from the bibliometric databases InCites and SciVal. Some of the data informing the investigation included, among others, journal titles in which UCT academics publish, the publication models (open, hybrid or closed) and faculty or discipline publishing trends.

\subsection{Methodology and analysis}

As pointed out by Kahn (2011), UCT has, over a sustained period, produced the largest number of research articles in South Africa. Therefore, UCT would make a good case study on publishing trends. According to Creswell (2014) and Denscombe (2012), case studies focus on one instance of a particular phenomenon with a view to providing an account of experiences or processes in that particular instance. Creswell (2014) makes the point that case studies are a design of inquiry in which the researcher develops an in-depth analysis of an activity or process, such as the publishing patterns at UCT being reported in this paper. Bless, Higson-Smith and Sithole (2013) state that, as much as case studies may be descriptive, they may also make use of quantitative data to determine a phenomenon, which supports the current inquiry.

The publishing trends of UCT researchers were investigated against the backdrop of OA policies and practices that have been developed and implemented at UCT. Denscombe (2012: 55) advises that case studies work best when researchers want to investigate an issue and "provide an explanation that can cope with the complexity and subtlety of real life situations". He goes on to explain that a case study lends itself to the study of processes and relationships within a setting and that the use of more than one research method sits comfortably within the case study approach.

A combination of data mining and bibliometrics research methods within a case study design was used to investigate the trends in publishing behaviour of UCT researchers. As indicated by Osei-Bryson and Rayward-Smith (2009), data mining is the extraction of hidden predictive information from large databases to identify trends and behaviours. Jackson (2002) adds that there are two types of data mining approaches and they differ depending on whether the researcher seeks to build models or to find patterns. This investigation used the second type, that is, the detection of patterns of behaviour through data mining which is a process of seeking 'nuggets' of information among the mass of data (Jackson 2002). The bibliometric component involved the measurement of data not intrinsic to the text, that is, analysis without the text being read. Instead, extrinsic measures were used, such as affiliation of author, journals in which articles are published, and whether they are open, hybrid or closed journals.

For the purposes of this investigation, bibliometric data were harvested from InCites, SciVal and UCT's accredited journal publication count for submission to the DoHET. InCites and SciVal facilitated searching by institutional affiliation to generate profiles for UCT researchers. The search enabled the identification of journals in which UCT researchers published, the top researchers and other publishing trends. InCites and SciVal index journals from Web of Science and Scopus databases respectively. Hence, a limitation in the identification of the total UCT publication count is that these indexes might not reflect all works published in accredited journals. To overcome this limitation, the results were supplemented with the publications count data from UCT's Research Office. The data from all three sources (InCites, SciVal and the DoHET list) were cleaned and analysed to provide further insight. Cleaning of data included correcting the ISSN numbers, confirming the publisher, and marking the journal statuses as either 'open', 'hybrid' or 'closed' (access through subscription only), as reflected in DOAJ, Sherpa/Romeo ${ }^{6}$ and on the journal websites themselves.

\subsection{Results and discussion}

What follows are the results of the study and discussions around the publishing trends that were discovered.

\subsubsection{Publishing trends overall}

The data from all three sources confirmed an overall increase in journal publication output by UCT researchers for the period 2011-2015. As may be seen in Figure 4, there has been a steady decrease in the number of closed journals being published while the number of totally open journals has increased. It is inferred that the publishing patterns of UCT researchers would be in alignment with the trends reflected in Figure 4.

\subsubsection{Journal publishing trends}

In analysing the data, the top ten journals in which UCT researchers published over the period 2011-2015 was established (see Table 1). All journal titles, with the exception of one (Astrophysical Journal), offer an OA option - be it gold or hybrid. In the main, UCT researchers are publishing in journals that offer an OA option. 
Figure 3 Percentage of journal models (open, hybrid, closed) published by year, according to the DoHET list

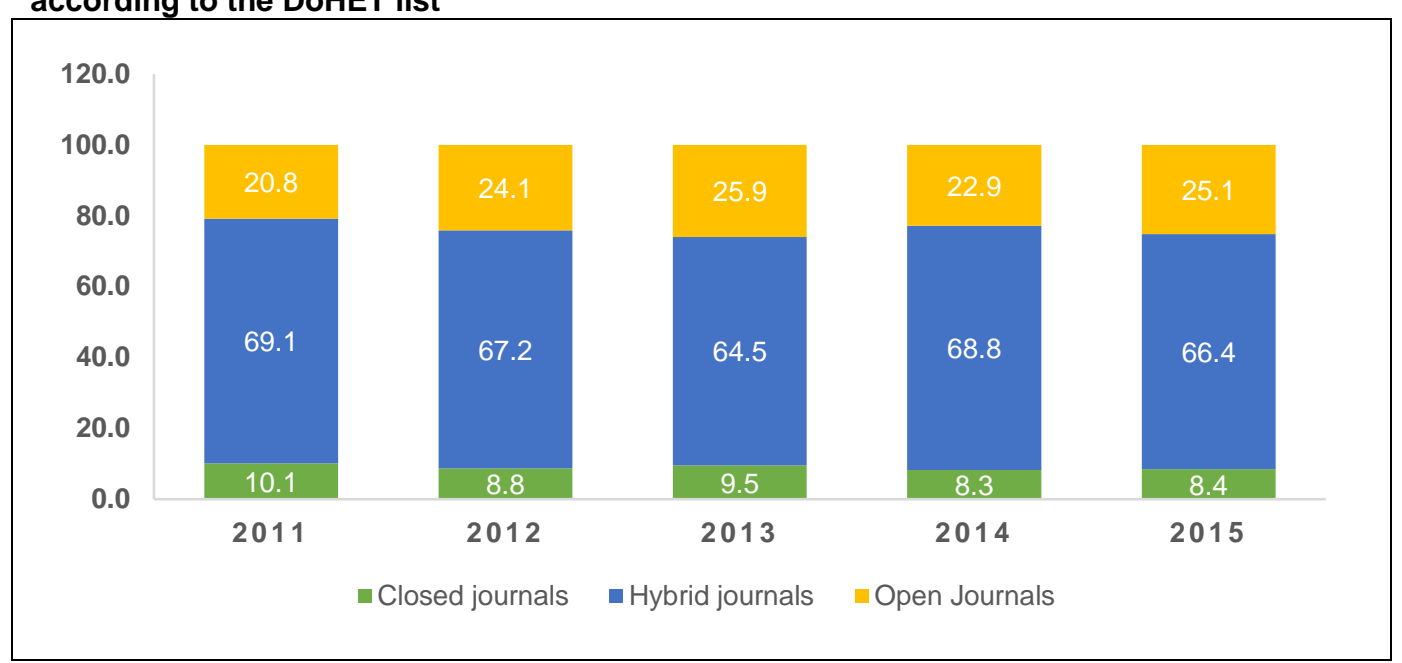

Table 1 A comparison of the top 10 journals as reflected in the three databases

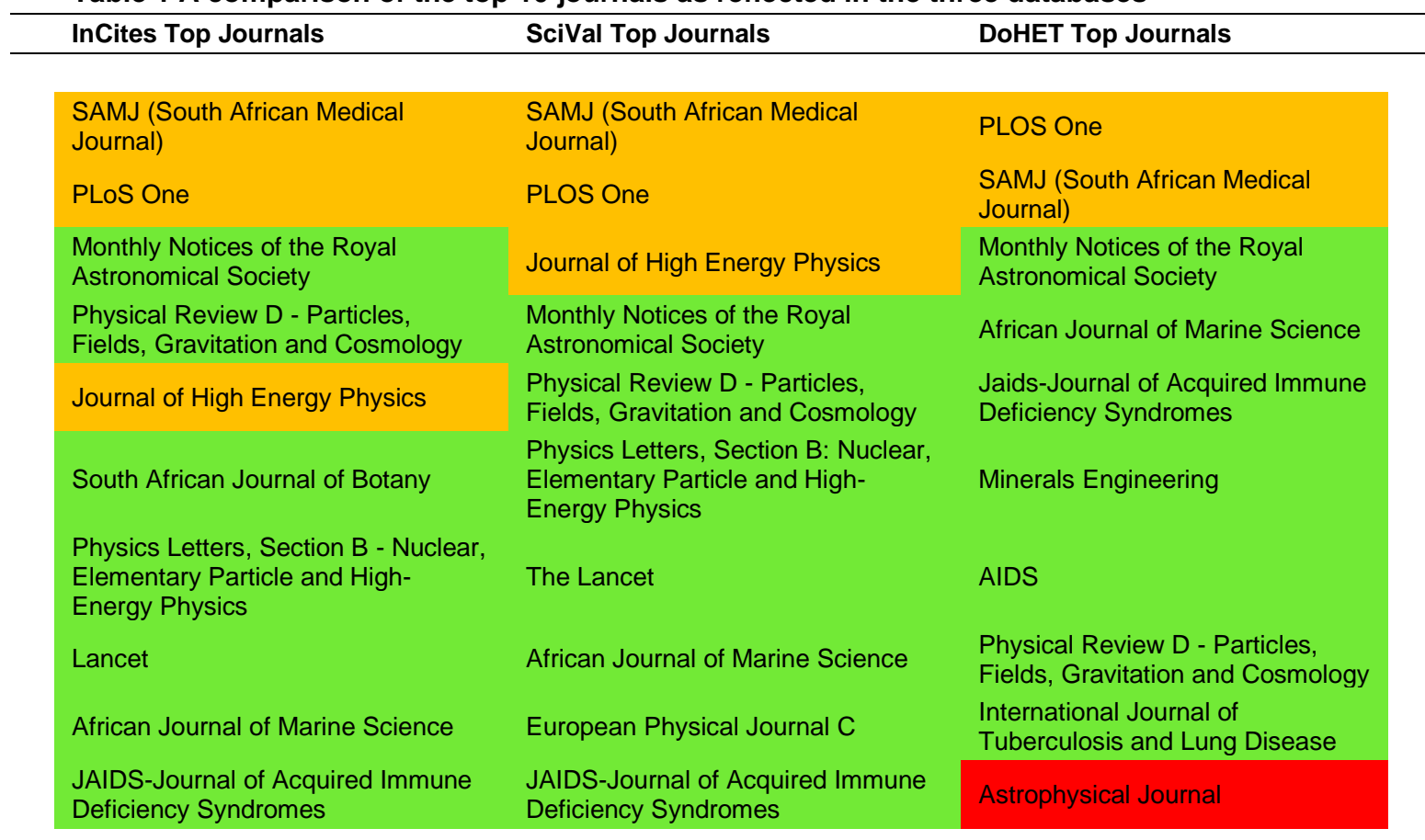

\section{\begin{tabular}{l|l|l} 
Completely open & Hybrid & Closed
\end{tabular}}

In Figure 5, there is clear evidence that researchers from UCT's Health Sciences Faculty publish in journals that offer an OA option. As much as the authors would like to attribute this trend to the policies and practises at UCT, it must be acknowledged that there has been a general movement by health sciences publishers to offer an OA option for their journals. On examination of Figure 5, it is evident that the only discipline where the closed journal model dominates is Law. The authors do not accept that this is so because of the nature of the discipline (see related discussion below) but that the challenge can be overcome by libraries extending their range of services to include library as a publisher services.

Figure 6 shows a significant increase since 2011 in the number of articles that are published OA by UCT researchers. In analysing the data gleaned from SciVal, InCites and the DoHET list, it is reassuring to see that the growth of OA articles is on the rise. In terms of data gleaned from InCites, there was an almost $77 \%$ increase in OA articles published by UCT researchers from 2011 to 2014 and an almost 61\% increase in open articles that appeared on the DoHET list. The growth in the number of OA articles is predominantly in the health sciences discipline - as explained earlier this discipline seems to be a pioneer in OA publishing. Overall, the fact that research information is accessible free to the end user contributes to the social justice agenda of UCT.

According to all three data sources, the top two journals in which academics at UCT choose to publish are gold OA journals (see Table 1). Of the sixteen titles that appear in an aggregated 'top 10 list', $18.25 \%$ are fully open and $75 \%$ are hybrid journals. Only one journal is completely closed. It is interesting to note that the top two journals appear on all three 
data sources as the two journals at UCT most published in. It is encouraging to note that critical medical research is freely accessible to all South Africans and Africans.

Despite the fact that the hybrid model is not the preferred model for the authors, if UCT academics continue to publish in hybrid journals, it does present the university with the option of making those articles freely available via its institutional repository. With the continuous development of repository infrastructure and support, it is anticipated that there will be growth in the number of items in the repository that would be freely accessible to all. Furthermore, there is expectation that, as the number of journals offering a gold OA option grows, UCT researchers will indeed publish in OA journals.

Figure 4 Number of articles published in different journal models by faculty

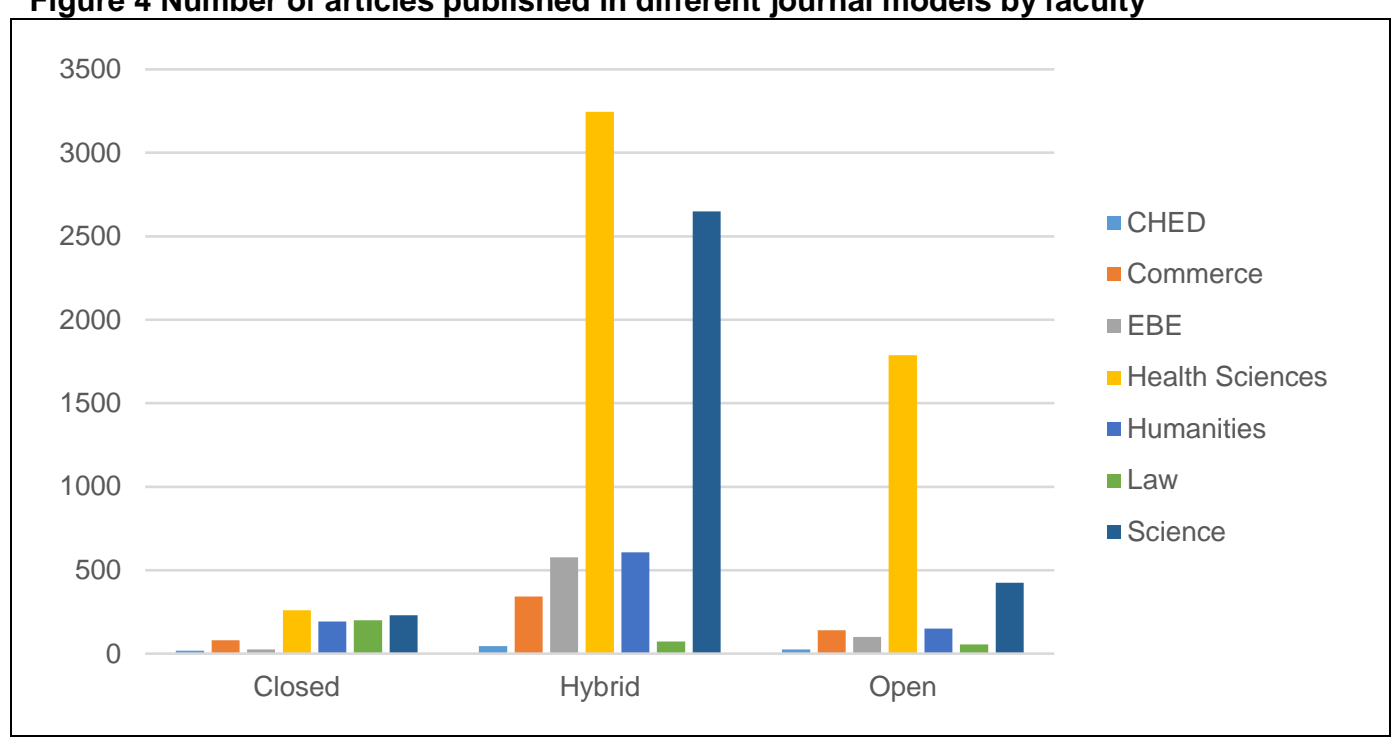

Figure 5 A comparison of the number of articles published via gold OA

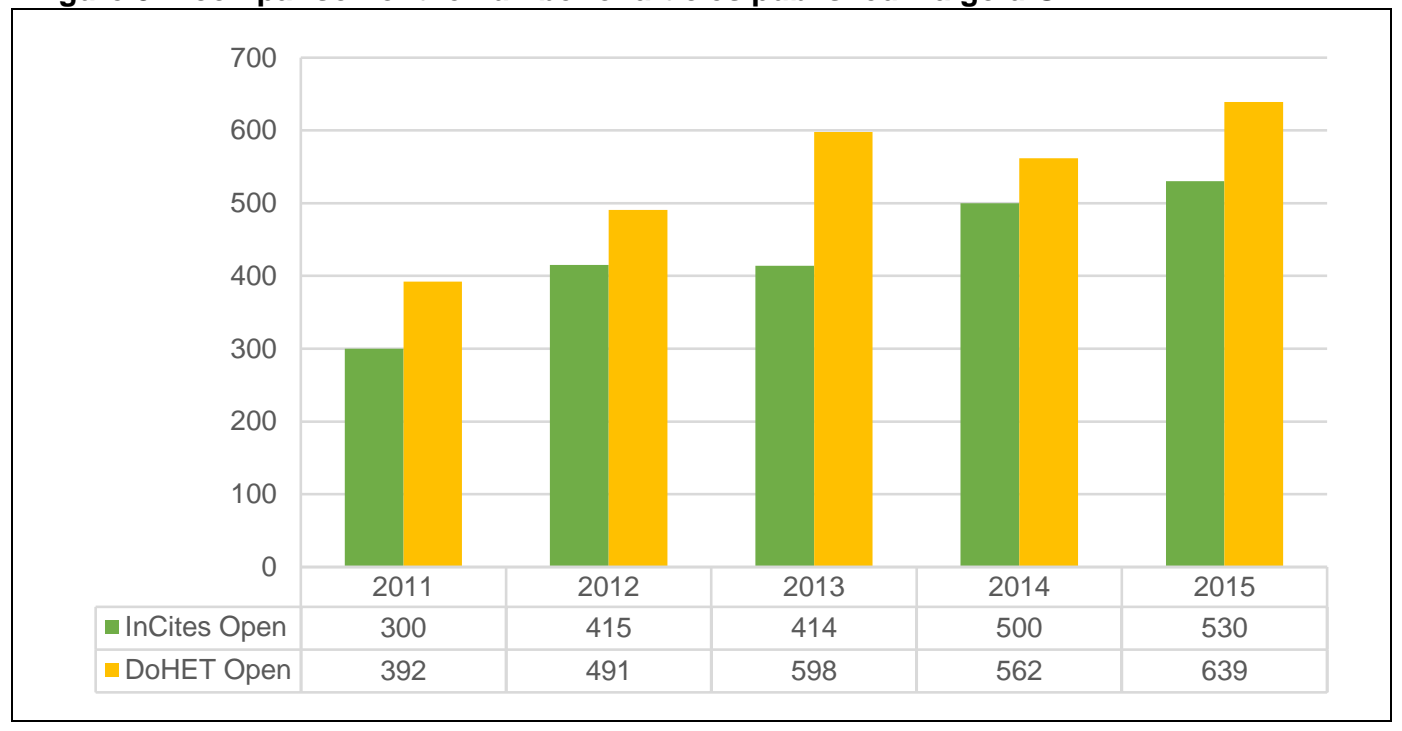

\subsubsection{Publishing trends per discipline/faculty}

An analysis of all three databases indicates that the majority of UCT's research is published in the discipline of Health Sciences (as mentioned previously). Figure 7 corroborates the earlier assertion that Health Sciences researchers publish in OA forums. The figure shows that, in the Health Sciences, the number of open titles are a significant contributor to the large number of articles that are published OA. The number of titles that are closed is small which, in effect, means that the researchers have more opportunities to publish open. A contributory factor to the high publication rate for Health Sciences in open forums is the APCs support provided by the university. The Library has a shared membership to BioMed Central, which gives the UCT author, particularly Health Science researchers, a 50\% discount on the APCs for publications in that stable. Figure 7 shows that, in the discipline of Law, the number of titles that are closed is significantly higher than for any other discipline. Therefore, the opportunity to publish open is smaller. Despite this challenge, UCT legal researchers have a higher open publication percentage than researchers in some of the other disciplines, demonstrating the will of legal researchers to publish $\mathrm{OA}$. Hence, it is here that the library needs to make greater contributions with regard to the library as a publisher service so that it can provide legal researchers with structures in which to publish open. 
Figure 6 Percentage of journal models (open, hybrid, closed) per faculty

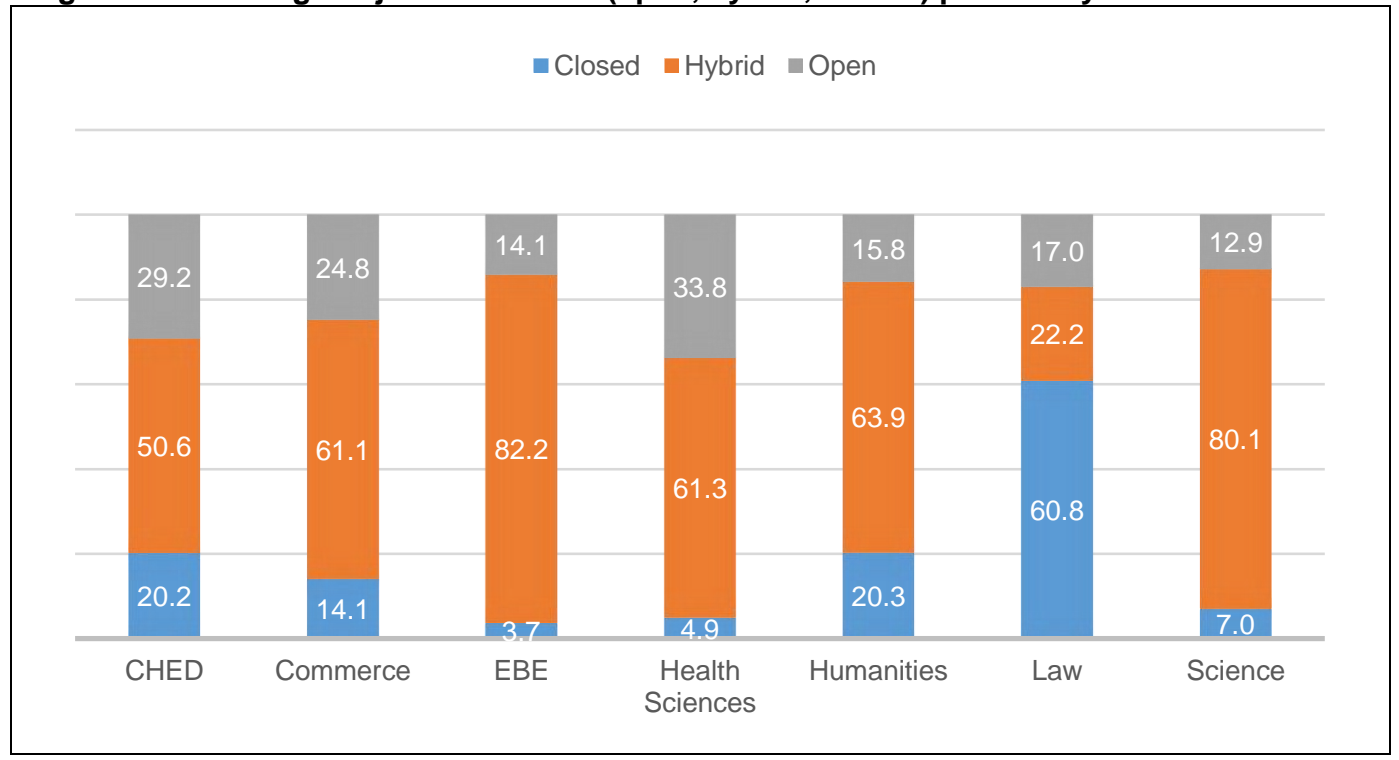

\section{Conclusions}

The essence of $\mathrm{OA}$, especially in the African context, is to contribute to social justice by making published research more accessible. In the traditional subscription process, the greater percentage of African institutions do not have access to critical content to generate new research. A vicious circle prevails in that funding is required to buy access to information for the generation of new knowledge or to support the growth of research. The visibility of research output is what contributes significantly to the acquisition of funding. Therefore, it is incumbent upon those African institutions who are financially better off than others and who are more steeped in a research culture to share their research openly for the holistic development of research on the African continent.

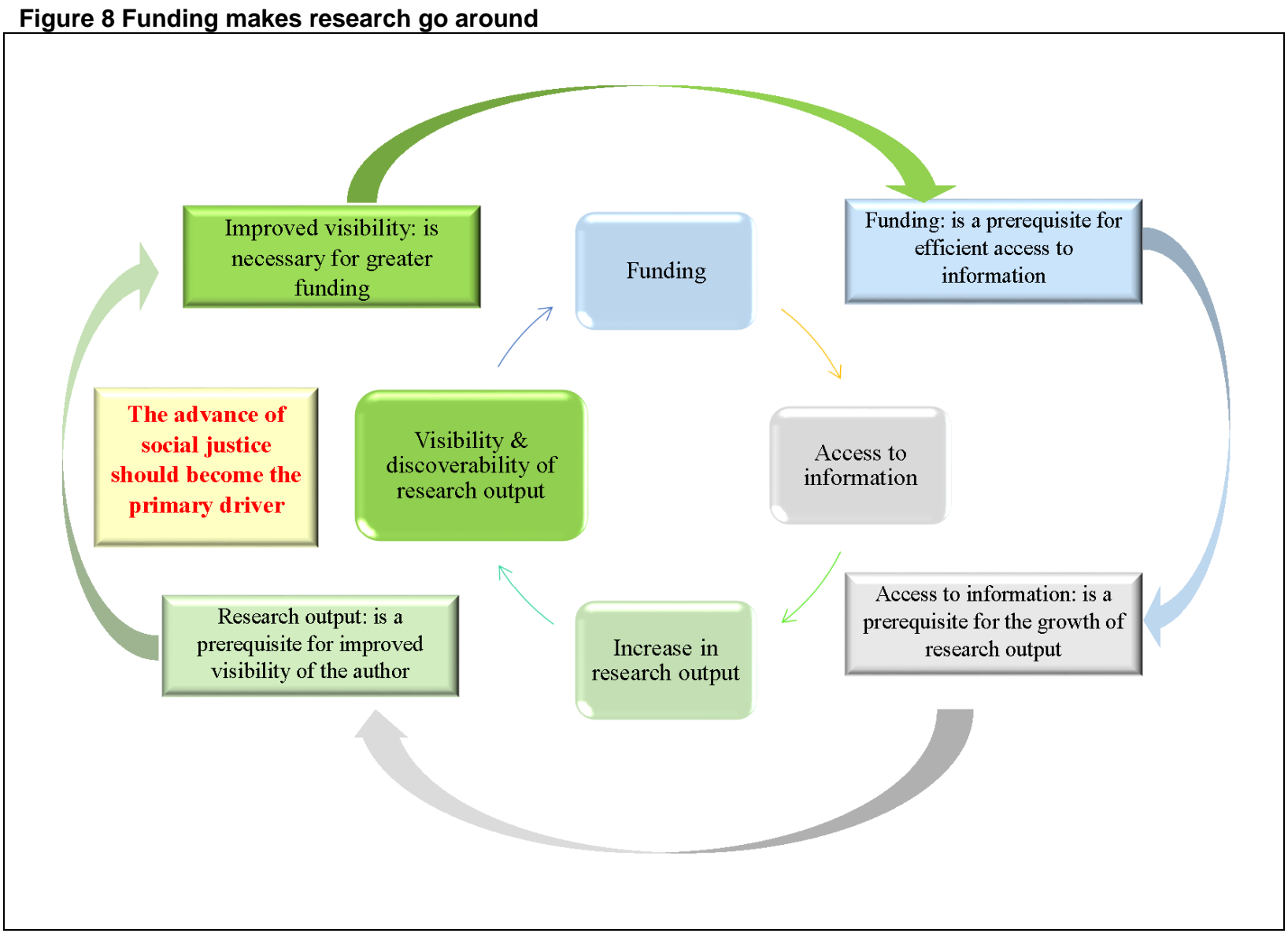

To firmly establish South Africa as a significant contributor to the changing African research landscape, the authors would like to recommend that there be a national OA policy monitored by the national Department of Science and Technology. In an effort to grow institutional and researcher commitment to OA, the authors would also like to recommend 
that the 'reward system' for accredited journal articles be revisited. It is suggested that national government deducts $50 \%$ of the publication reward for work published in journals that are not OA. Furthermore, those articles that are published in journals that are completely OA should receive an additional percentage added to the 'normal' reward amount. It is the view of the authors that these recommendations will provide the South African government with better return on investment when it comes to research.

UCT, a relative newcomer to the openness movement, has done well over the last few years to gain lost ground in this arena and is now among the leading institutions on the continent with regard to sharing its research output via OA platforms. There are a number of contributory factors to this accelerated growth of openness at UCT; some of these include a progressive OA policy and related activities that ensure roll-out of the policy. The commitment to supporting APCs en route to developing a culture of publishing OA is another positive for UCT. The growth of the openness movement itself has allowed greater opportunities, in terms of a larger number of open journals, in which UCT researchers can publish.

As much as there has been no significant movement away from the 'publish or perish' tradition, another substantial cliché influencing publishing patterns is 'visibility breeds funding'. As a leading research university on the African continent, UCT researchers have to adapt quickly to forums that give them the greatest visibility to improve their chances of securing greater funding for continuation of their research programmes (see Figure 8). In an era of fiscal constraints, where visibility of research is an important funding leverage, adapting to new publishing trends is no longer an option but an imperative.

\section{References}

Annan, K. 2000. Information technology should be used to tap knowledge from greatest universities to bring learning to all. Press release: No UNIS/SG/2625. [Online]. http://www.unis.unvienna.org/unis/pressrels/2000/sg2625.html.

Björk, B.C. and Solomon, D. 2014. How research funders can finance APCs in full OA and hybrid journals. Learned Publishing, 27(2): 93-103.

Bless, C., Higson-Smith, C. and Sithole, S. 2013. Fundamentals of social research methods: an African perspective. Cape Town: Juta.

Budapest Open Access Initiative. 2002. Budapest Open Access Initiative. [Online]. http://www.budapestopenaccessinitiative.org/read

Chadwell. F.A. and Sutton, S.C. 2014. The future of open access and library publishing. New Library World, 115(5/6): 225-236. DOI:10.1108/NLW-05-2014-0049.

Chaplin, K. 2006. The Ubuntu spirit in African communities. [Online]. http://www.activateleadership.co.za/hive/original/561416a000ff4.pdf (16 November 2016)

Chiware, E. and Skelly, L. 2016. Publishing patterns at the Cape Peninsula University of Technology. South African Journal of Science, 112(1/2). DOI:10.17159/sajs.2016/20140220.

Creswell, J.W. 2014. Research design: qualitative, quantitative and mixed methods approach. $4^{\text {th }}$ ed. London: Sage.

Crow, R. 2002. The case for institutional repositories: a SPARC position paper. [Online]. http://www.sparc.arl.org/sites/default/files/media_files/instrepo.pdf.

Denscombe, M. 2012. The good research guide: for small-scale social research projects. Open University Press: Berkshire, England.

Directory of Open Access Journals (DOAJ). 2016. Directory of Open Access Journals (DOAJ). [Online]. https://doaj.org/

Eger, T., Scheufen, M. and Meierrieks, D. 2015. The determinants of open access publishing: survey evidence from Germany. European Journal of Law and Economics, 39:475-503. DOI:10.1007/s10657-015-9488-x.

Ilva, J., Laitinen, M.A. and Saarti, J. 2016. The costs of open and closed access: using the Finnish research output as an example. LIBER Quarterly. 26(1): 13-27. DOI:10.18352/lq.10137.

International Forum for Social Development. 2006. Social justice in an open world: the role of the United Nations. New York: United Nations.

Jisc, 2012. Benefits of OA to scholarly research to the public sector: a report for the Open Access Implementation Group. Final report: 12 March 2012. London: Jisc. [Online]. http://wiki.lib.sun.ac.za/images/e/e3/Report-to-oauk-benefits-of-open-access-public-sector.pdf (18 November 2015).

Jackson, J. 2002. Data mining: a conceptual overview. Communications of the Association for Information Systems, 8: 267-296 [Online]. https://pdfs.semanticscholar.org/d571/f03856b2d6647ed01edbab0f13830eb50127.pdf (12 September 2016).

Kahn M. 2011. A bibliometric analysis of South Africa's scientific outputs: some trends and implications. South African Journal of Science, 107(1/2). DOI:10.4102/sajs.v107i1/2.406.

Laakso, M. and Björk, B.C. 2016. Hybrid open access: a longitudinal study. Journal of Informetrics, 10(4): 919-932.

Lee-Hwa, T., Abrizah, A. and Noorhidawati, A. 2012. Availability and visibility of open access digital repositories in ASEAN countries. Information Development, 29(3): 275-285.

Miller, D. 1999. Principles of social justice. Cambridge, MA: Harvard University. [Online]. http://rebeccaginsburg.net/Rebecca_Ginsburg/Social_Justice_files/Miller,\%20Principles\%20of\%20Social\%20Justice. pdf (10 October 2016).

National Research Foundation (NRF). 2015. Statement on Open Access to Research Publications from the National Research Foundation (NRF)-Funded Research. [Online]. http://www.nrf.ac.za/sites/default/files/documents/oastatement_2015.pdf (1 February 2017).

Osei-Bryson, K. and Rayward-Smith, V. 2009. Data mining and operational research: techniques and applications. Journal of the Operational Research Society, 60 (8): 1043-1044. DOI:10.1057/jors.2009.16. 
Park, J-H. and Shim, J. 2011. Exploring how library publishing services facilitate scholarly communication. Journal of Scholarly Publishing, 43(1): 76-89. [Online]. http://muse.jhu.edu/journals/journal_of_scholarly_publishing/summary/v043/43.1.park.html (16 December 2016).

Parker, R. 2012. What the library did next: strengthening our visibility in research support. Proceedings of 'eM-powering eFutures', the 16th Biennial VALA Conference and Exhibition. 6-9 February. Melbourne, Victoria: VALA. 1-17. [Online]. http://researchbank.swinburne.edu.au/vital/access/manager/Repository/swin:26132 (1 November 2016).

Raju, R., Raju, J. and Claassen, J. 2015. Open scholarship practices reshaping South Africa's scholarly publishing roadmap. Publications, 3(1). DOI:10.3390/publications.

Rawls, J. 2014. Theory of justice as fairness. In. Philosophy of justice, contemporary philosophy. G. Floistad, Ed. 311328. [Online]. http://www.follesdal.net/ms/Follesdal-2014-Rawls-JasF.pdf (10 October 2016).

Robinson, M. 2016. What is social justice? [Online]. http://gjs.appstate.edu/social-justice-and-human-rights/what-socialjustice (20 December 2016).

Tise, E. 2011. Strengthening African higher education through the dissemination of research content: the role of the library. Paper presented at the Association of African Universities - Conference of Rectors, Vice Chancellors and Presidents of African Universities. 30 May - 3 June 2011. Stellenbosch, South Africa.

University of Cape Town. 2011. Intellectual Property Policy. [Online]. https://www.uct.ac.za/downloads/uct.ac.za/about/policies/intellect_property.pdf (12 December 2016).

University of Cape Town. 2014. Open Access Policy. [Online]. http://www.uct.ac.za/downloads/uct.ac.za/about/policies/OpenUCT_Policy.pdf (12 December 2016). 